\title{
Study on the Transmission of Japanese Animation Culture
}

\author{
Yurun Huang ${ }^{1, a}$
}

${ }^{1}$ School of Digital Media and Artistic Design, Beijing University of Posts and Telecommunications, Beijing 100876, China

a386763378@qq.com

Keywords: Japanese animation, Animation industry, Culture transmission.

\begin{abstract}
With the rapid development of the global economy and society, animation has been more and more attention as the significant branch of the culture industry throughout the world. Based on the analysis of the development trend of Japanese animation market, this study mainly discussed the attributes expressed by contemporary Japanese animation and the transmission of Japanese animation culture. And hoping to bring good inspiration for the development and communication of Chinese animation industry.
\end{abstract}

\section{Introduction}

With the development of world economy, the culture of different countries and different nations can communicate more frequently and deeply. The cultural factors become more and more important in the economic operation. The economic benefits of culture have become the important indicators of measuring national comprehensive strength. As one of the core of cultural industry, the animation industry is the concentrated reflection of knowledge economy, highly fit into the post-industrial era and knowledge economy era of industrial upgrading and innovation, represents the trend of the development of the cultural industry in the future[1]. The animation industry creates economic values through the integrate of the originality and variety of knowledge, and rich connotation of culture. In the past twenty years more than $60 \%$ of the worldwide animated movies and television were produced by Japan ever since it made access to western countries by means of animation export[2]. Even in contemporary global media market, Japanese animation or animation brings about one third of the total animation industrial income. And it has been translated into more than thirty languages and widely propagated in the global world that diverse animation clubs have been built up by their royal fandom in every continent. The cross-cultural communication of Japanese animation is very typical and successful with strongly supported by Japanese government with considerable income paid back[3]. Therefore, the research and study on the communication and developing mode of Japanese animation culture can bring good inspiration for the development and communication of Chinese animation industry.

\section{The development trend of Japanese animation market}

The development trend of TV animation. According to the statistical data of the association of Japanese animation(AJA), since the late 1990s, the production of Japanese domestic animation increased sharply and reached to peak at 2006 before slid. The amount of domestic animation began to rebound in 2010 and keep growing since then. The growing trend of the movie animation amount in Japanese presents similar trends. After the bottleneck period in 2006, the animation production industry has recovered again, the production quantity is up to standard. According to the data of Japanese film association, a large portion of animation income comes from the DVD made by animation vendors. In 2005, the sales of animation software are 9.71 billion yuan, about $47 \%$ of the total income of industry.

The development of the movie animation and opera version animation. The production time of the opera version animation in year 2012 is the longest since 2000. After the bottleneck period of the animation product in Japan, the income of movie animation began to increase since 
2009, the key and sight of animation industry is turned to movie animation production. Recent years, the sales of the media model which as the reuse of TV animation is standstill, which caused certain risks for the industry. Therefore, the movie animation and opera version animation which rely on the movie screen began to become the focus of the industry. The year 2012 is a bumper year for opera version animation, the total income reached up to 40.9 billion yen, $43.5 \%$ increase over the previous year. As to the top 20 of which the box-office receipts amounted to billions yen in 2013, the top 4 were all animation, the top was The Wind Rises produced by Toho Studios, of which the box-office was 12 billion. With the addition of other animation movies, there are seven animation productions which is also a shocking phenomenon even in the international film market.

The development of fans market and new media. The commercialization of animation constitutes a big part of industry sale. Long before the year 2002, the end user consumption of animation derivative product was up to 435 billion yen. In 2012, the market size of commercialization of animation characters in Japan was about 612 billion yen. Markets face to children and families were advanced steadily. In the meantime, the commercialization of animation market focus on the core fans and adults is significantly broad. Although the commercialization of animation market primarily faces children and family, but the adult consumption group began to notable. The animation software associate with new media such as the download video viewing mode is becoming the main current.

\section{The attributes expressed by contemporary Japanese animation}

In the development of Japanese animation, the attributes of animation are deeply associate with the external environment and industrial environment. The trend of the attributes is gradually incremental with the adapt to the environments. Under the background of "cultural state" strategy, comprehensive characteristics of Japanese animation attribute is more apparent.

In the expression of education attribute, although the violence and sex element becomes one of denounce in Japanese animation, but most theme of the animation product is poetic justice, and has strong heuristic education for young children. In the expression of commercial attribute, the exploit and sales of animation and related product shoulder the historical mission to revive the economy. In the expression of social attribute, animation becomes the leader of popular culture, it can grasp the era trend and affect the value concept. In the expression of political attribute, animation becomes the good way to spread Japanese culture, the way of changing diplomacy, and the way to promote the core strength of the country.

The political attribute is more prominent in the contemporary Japanese animation. On one hand, by extending the play approach and the market abroad, it can expand the global influence of Japanese animation, carry forward the traditional Japanese culture, and enhance teenagers' identity to Japan around the world. On the other hand, in the spread of Japanese culture, it can change the inherent pattern of diplomatic through soft characteristics of cultural and enhance Japan's international political position.

\section{The transmission of Japanese animation culture}

As an island country, Japan developed unique national cultural through the succession of the local culture and the references of other advanced culture. Just because Japan is far away from western countries, therefore, in a long time, Japan is as a strange and mysterious to western country which know very little about its culture. Since the Meiji restoration, Japan actively learning the west science and technology and advanced culture, also pay attention to the output of their local culture in order to make the world understand and recognize its culture. As only a Japanese country in the world, language barriers affect the spread of Japanese culture around the world. While animation as a visual art, overcomes the language barriers during the culture spread, and construct a new way for Japanese cultural transmission.

The transmission in the embryonic stage. From the angle of the Japanese animation development history, animation as a cultural form began to transmit to abroad since the embryonic 
stage of Japanese animation. According to the film magazine in Taishō period, the animation Momotaro created by Kitayama Seitarō which expert to Franc at 1917 was the first animation output overseas documented in the history of Japanese animation. Considering the position and environment of Japanese animation at that time, the purpose of early output of the animation product is to let the world aware the existence of Japanese animation. Furthermore, the first output of Japanese gained good reputation from the world, which is directly related with the artistic quality of the works, but more factors may be the identity of the foreign culture.

The three early minister animated movies of Toei animation awarded in the world wide and also obtained the overseas income for the first time, which reflects the attribute of commercial value of Japanese animation. The themes of the first three output animation are all draw materials from oriental culture. Those works combined the beautifully smooth picture with bizarre story along with colorful

traditional Japanese customs, which depicted a space different from the European and American works of animation for fans of animation in the Japanese and the rest of the world, perfect showed the traditional Japanese culture throughout the world.

The transmission in the rapid growth stage. The emerge of TV animation provides a new media for the transmission of Japanese animation, and also becomes a new approach to transmit Japanese culture. In 1963, the astro boy began to show in America which achieved high audience rating. In the 1970s, under the drive of the dramatic growth in Japanese TV animation production, more animation works began to step towards the world, occupied $60 \%$ share of the global animation broadcast market. In order to conform to global audience's aesthetic needs and values, the output of the animation at this stage mainly embodies the world culture. Animations like The Alps Girl Hattie with the European and American literature genre, the mythological Dragon Ball were greatly welcomed by the European and American audiences.

Japanese animation was approved by the world is part because of the broadcast animation enterprise business practices to get the play income of overseas, while the other part is because of the political behavior to broad the influence of Japan. In this stage, the cultural expression in animation is mainly the combination of local and other countries' culture, presents the common characteristics of culture, but it's mainly the expression of commercial attribute not the political attribute.

The transmission in the mature stage. The hot sale of the Ghost in the Shell created by Mamoru Oshii in American and the broadcast of Neon Genesis Evangelion created by Anno Hideaki are the symbols for Japanese animation to come to the mature stage. The sale of Ghost in the Shell in United States increased enormously which enhanced the Japanese government and people's confidence of the domestic animation. With the expansion of the Japanese animation in the overseas, Japanese animation has already formed the global cultural consumption trend. Under the government's vigorously support, Japanese animation increases the output to overseas, at the same time it more focuses on the combination of Japanese traditional culture into the creation which makes the animation become the effective carrier of the domestic culture[4].

In this stage, appeared many animation producers and animation works with a performance of traditional culture and national consciousness. Representable animation masters like Miyazaki Hayao, Mamoru Oshii, and Katsuhiro Otomo are all pay attention to show the concept of Oriental culture. Animation works like Millenium Actress created by Satoshi Kon, the Kumo no mukô, yakusoku no basho created by Makoto Shinkai all have a strong Japanese national characteristics and national style.

The transmission in the new period stage. In the information age, the regional boundaries have been unable to prevent the spread of culture. As more Japanese animation which shows the inherent culture and concept of its culture is popular in overseas, Japanese animation has started to focus on the ideology and values changes instead of business interests from the past. This change means that Japanese traditional culture is accepted and cognitive by the world while at the same time Japan's national status also got corresponding improvement. Japan has shifted from a big animation production country to a powerful cultural output country. In manufacturing for the world 
of entertainment, it also conveys their native culture which deeply affects the audience identity of Japan and Japanese culture. As a form of cultural spread, Japanese animation using modern media to penetrate into ordinary people's life and entertainment under the guidance and support from the government.

\section{Conclusion}

The transmission of Japanese animation culture is significantly deep in the world, which make the animation industry developed rapidly. However, under the influence of social factors like the hollowing out, ageing and the low birth rate, about the future trend of Japanese animation, scholars have expressed doubt. The focus of the problem mainly the temporary shortage of excellent animation producers and the deterioration of domestic creation environment. While the quickly development of Chinese and Korean animation industry causes great threat to the sustainable development of Japanese animation in the future. Therefore, in the new stage, Japanese animation industry must find out new approaches to deal with the internal and external threats.

\section{References}

[1].Price, S., Cartoons from Another Planet: Japanese Animation as Cross - Cultural Communication. Journal of American \& Comparative Cultures, 2001. 24(1 - 2): p. 153-169.

[2].McCarthy, H., The Anime Movie Guide: Movie-by-Movie Guide to Japanese Animation since 1983. 1997.

[3].Sabin, R., Manga: Sixty Years of Japanese Comics. Journal of Design History, 2005. 18(2): p. 222-224.

[4].McCarthy, H. and O. Tezuka, The art of Osamu Tezuka: god of manga. 2009: Ilex. 